\title{
Treat or Eat: Food Insecurity, Cost-related Medication Underuse and Unmet Needs
}

\section{Citation}

Berkowitz, Seth Aloisi, Hilary K. Seligman, and Niteesh K. Choudhry. 2014. “Treat or Eat: Food Insecurity, Cost-Related Medication Underuse and Unmet Needs." American Journal of Medicine 127 (4): 303-310. doi:10.1016/j.amjmed.2014.01.002.

\section{Published Version}

doi:10.1016/j.amjmed.2014.01.002

\section{Permanent link}

http://nrs.harvard.edu/urn-3:HUL.InstRepos:36878927

\section{Terms of Use}

This article was downloaded from Harvard University's DASH repository, and is made available under the terms and conditions applicable to Other Posted Material, as set forth at http:// nrs.harvard.edu/urn-3:HUL.InstRepos:dash.current.terms-of-use\#LAA

\section{Share Your Story}

The Harvard community has made this article openly available.

Please share how this access benefits you. Submit a story.

\section{Accessibility}


Abstract

Background: Adults with chronic disease are often unable to meet medication and/or food needs, but no study has examined the relationship between costrelated medication underuse and food insecurity in a nationally representative sample. We examined which groups most commonly face unmet food and medication needs.

Methods: Cross-sectional analysis of data from chronically ill participants (self report of arthritis, diabetes mellitus, cancer, asthma, chronic obstructive pulmonary disease, stroke, hypertension, coronary heart disease, or presence of a "psychiatric problem"), age $\geq 20$ years, of the 2011 National Health Interview Survey. We fit logistic regression models to identify factors associated with food insecurity, costrelated medication underuse, or both.

Results: 9,696 adult NHIS participants reported chronic illness; $23.4 \%$ reported cost-related medication underuse; $18.8 \%$ reported food insecurity; and $11 \%$ reported both. Adults who reported food insecurity were significantly more likely to report cost-related medication underuse (adjusted odds ratio [aOR] 4.03). Participants with both cost-related medication underuse and food insecurity were more likely to be Hispanic (aOR 1.58) non-Hispanic Black (aOR 1.58), and have more chronic conditions (aOR per additional chronic condition 1.56) than patients reporting neither. They were also less likely to have Public, non-Medicare insurance (aOR 0.70) and report to WIC participation (aOR 0.39). 
Conclusions: Approximately 1 in 3 chronically-ill NHIS participants are unable to afford food, medications, or both. WIC and public health insurance participation are associated with less food insecurity and cost-related medication underuse. 


\section{Introduction}

The current economic climate has led to substantial hardship for many Americans. In 2012, one in six Americans report that they lack health insurance(1) and nearly one in five report trouble meeting basic needs(2). As a result, approximately $15 \%$ of chronically ill Americans report cost-related medication underuse, which refers to taking less medication than prescribed, or not taking it at all, due to $\operatorname{cost}(3,4)$. An equal proportion of American households(5) experience food insecurity, which is defined as "limited or uncertain availability of nutritionally adequate and safe foods, or limited or uncertain ability to acquire acceptable foods in socially acceptable ways(6)".

While prescription drug benefit programs and food security assistance programs, such as the Supplemental Nutrition Assistance Program (SNAP, formerly the Food Stamp Program) do exist, it is not clear if they are sufficient to mitigate the effects of food insecurity on medication underuse or the effects of out-of-pocket medication payments on food insecurity.

Both cost-related medication underuse and food insecurity are associated with adverse health consequences,(7-10) but no prior study has examined the relationship between them in a nationally representative sample. We used the 2011 National Health Interview Survey to understand how common these two aspects of economic insecurity are among individuals with chronic disease and, to inform policy-making, whether specific groups of patients, when both needs cannot be met, are more likely to report food insecurity, or vice versa. 


\section{Methods}

Data Source and Study Sample

We analyzed data from the 2011 National Health Interview Survey (NHIS)(11). The NHIS is conducted annually by trained in-person interviewers in English, Spanish, or with an interpreter. Full details of NHIS methodology have been previously described(12). To focus on participants with chronic illness, who may be forced to choose month after month between medications and food and for whom such tradeoffs may have important clinical consequences, we included adult participants (age $\geq 20$ years) in the 2011 NHIS who report at least one of 8 common chronic conditions surveilled by the NHIS: arthritis, diabetes mellitus, cancer, asthma, chronic obstructive pulmonary disease (COPD), stroke, hypertension, coronary heart disease, or presence of a "psychiatric problem". For subgroup analyses, we created the following groups: cardiovascular disease or hypertension, defined as participants reporting hypertension, coronary heart disease (including myocardial infarction), or stroke; diabetes mellitus; non-cardiovascular disease (asthma, COPD, arthritis, or cancer); and presence of a "psychiatric problem". We also conducted sensitivity analyses using all adult participants, regardless of whether they reported a chronic illness.

The Partners HealthCare Human Research Committee exempted this study from review.

Food Insecurity Assessment 
Food insecurity was assessed using the 10 adult-referenced items of the United States Department of Agriculture (USDA)'s household-level 30-day food security scale. These items are used to ascertain national rates of food insecurity(6). We dichotomized responses into Food Secure (affirmative response to 0-2 items) and Food Insecure (affirmative response to 3-10 items) according to standard protocol(6).

\section{Cost-Related Medication Underuse}

Cost-related medication underuse was determined by response to four validated items adapted from the Medication Expenditure Panel Survey(13). Similar to prior studies(14), a respondent was considered to have cost-related medication underuse if he or she responded 'Yes' to any of 4 items which asked if, in the last 12 months, 1) there was a prescription a participant did not fill due to cost, 2) the participant skipped medication doses to save money, 3) the participant took less medication than prescribed to save money, or 4) the participant delayed filling a prescription to save money.

\section{Demographic and Socioeconomic variables}

We adjusted for several demographic and socioeconomic variables that may be associated with food insecurity and/or cost-related medication underuse $(4,9)$. Demographic factors included age (in years), gender, self-report race/ethnicity (non-Hispanic white, non-Hispanic Black, Hispanic, or other/mixed race/ethnicity), and nativity status (born in the United States or not). We categorized health 
insurance status with regard to both source and presence of a prescription drug benefit. Because almost $90 \%$ of Medicare beneficiaries have creditable prescription drug coverage(15), and prescription drug benefits are offered by Medicaid in all 50 states(16), we categorized patients into 5 mutually-exclusive insurance groups: none, private with drug benefit, private without drug benefit, Medicare, and other non-Medicare public insurance (including Medicaid, Medicare/Medicaid dual eligible respondents, and Veterans Administration coverage). For socioeconomic factors, we categorized educational attainment as less than high school diploma, high school diploma, or some college or higher. We classified income as a percentage of the federal poverty level (FPL), which accounts for household size, in categories of $\leq 100 \%, 101-200 \%$ FPL, and $\geq 200 \%$ FPL. We also ascertained selfreported household participation in the two main federal nutrition assistance programs, the Supplemental Nutrition Assistance Program (SNAP, formerly the Food Stamp Program) and the Special Supplemental Nutrition Assistance Program for Woman, Infants, and Children (WIC).

Clinical and other Variables

Because the number of chronic medical conditions that a patient has is associated with a higher likelihood of cost-related medication underuse(4), we constructed an index of the number of chronic medical conditions, similar to the method of Madden et al(4). As above, these conditions included arthritis, diabetes mellitus, cancer, asthma, COPD, stroke, hypertension, coronary heart disease, or presence of a "psychiatric problem". We also adjusted for tobacco use because the 
cost associated with this may lead to food insecurity and/or cost-related medication underuse, categorized as current, former, and never users based on self-report.

\section{Statistical Analysis}

Unadjusted comparisons were made using chi-squared tests for categorical variables and t-tests for continuous measures. We then used multivariable logistic regression to test our hypothesis that food insecurity was independently associated with cost-related medication underuse, adjusting for the demographic, social, and clinical variables described above. In order to see if these results, obtained in a chronically ill population, were generalizable to the overall American population, we then fit a model with the same variables but in all adult NHIS participants who were asked food security and cost-related medication underuse questions.

We also hypothesized that participation in insurance programs with lower prescription medication co-pays, such as Medicaid, or programs that reduced out-ofpocket spending for food, such as WIC, might be associated with lower food insecurity and lower cost-related medication underuse. In order to test these hypotheses, we fit three multivariable logistic regression models comparing those with food insecurity but not cost-related medication underuse, those reporting costrelated medication underuse but no food insecurity, and those reporting both with those who report neither food insecurity nor cost-related medication underuse.

Finally, in order to understand what factors were associated with unmet food and medication needs in situations where both cannot be fulfilled, we fit multivariable logistic regression models comparing those who were food insecure 
but did not report cost-related medication underuse to those who reported costrelated medication underuse but were not food insecure. This represents a group that may be subject to a "treat or eat" trade-off between prescription medication and household food. We also conducted this analysis among participants with incomes $<200 \%$ of the FPL in order to capture a more homogenous population with few resources--those for whom a "treat or eat" trade-off would be most likely.

Analyses were conducted using SAS version 9.3 (Cary, NC) survey procedures with domain analyses to account for the complex multistage sampling design and provide appropriate weights, as recommended in the 2011 NHIS data release documentation(17).

Results

Our sample comprised 9,696 adults who reported chronic illness. Overall, $23.4 \%$ of respondents, representing approximately 7.2 million Americans, reported cost-related medication underuse in the prior 12 months. In addition, $18.8 \%$ of respondents, representing 5.8 million American households, reported food insecurity. More than $11 \%$ of respondents reported both food insecurity and costrelated medication underuse. The baseline characteristics of our sample, stratified by the presence of cost-related medication underuse, food insecurity, both or neither, are presented in Table 1. Those with no cost-related medication underuse or food insecurity were older, more likely to be white, and had higher incomes than those in the other groups. Poverty was more common among those participants 
reporting food insecurity. Lack of insurance was more prevalent in groups with cost-related medication underuse.

\section{Relationship between cost-related underuse and food insecurity}

Cost related medication underuse was more common in respondents with food insecurity compared to those without (55.5\% vs. $16.0 \%, \mathrm{p}<.001)$. After adjustment for demographic factors, insurance, and clinical comorbidities, food insecurity remained strongly associated with cost-related medication underuse (OR 4.03 95\%CI 3.44, 4.73) (Table 2). The odds ratio was similar in a model including all adult NHIS participants, not only those with chronic disease (eAppendix Table A). The observed association was also similar when looking at the individual subtypes of cost-related medication underuse (adjusted for the same covariates as above): unable to afford a prescription (OR $4.1595 \%$ CI 3.52, 4.89), delaying a prescription due to cost (OR $4.0195 \%$ CI 3.38, 4.76), skipping doses due to cost (OR $3.4395 \%$ CI $2.90,4.06$ ), and taking less medication than prescribed due to cost (OR $3.6495 \%$ CI $3.06,4.33)$. Finally, the results were similar when looking at four subgroups of chronically ill patients: those with cardiovascular disease or hypertension, those with diabetes, those with non-cardiovascular disease (asthma, COPD, arthritis, or cancer) and those who reported history of a "psychiatric problem" (eAppendix Table B).

Risk factors for cost-related medication underuse, food insecurity, or both 
Compared to participants with neither cost-related medication underuse nor food insecurity, participants reporting both were more likely to be Hispanic, nonHispanic Black, have no usual place of care, have no insurance, and have more chronic conditions (Table 3). These participants were also less likely to have public, non-Medicare insurance and to be WIC beneficiaries.

Individuals reporting only food insecurity were more likely to be Hispanic, non-Hispanic Black, and have more chronic conditions, but were less likely to be WIC beneficiaries, than adults reporting neither food insecurity nor cost-related medication underuse. Adults reporting only cost-related medication underuse were more likely to have no insurance and more chronic conditions.

Finally, we conducted an analysis among those reporting only cost-related medication underuse but not food insecurity and those reporting only food insecurity but not cost-related medication underuse(Table 4). Participants who were Hispanic and non-Hispanic Black were less likely to report cost-related medication underuse, but more likely to report food insecurity, while adults who met food but not medication needs were more likely to have dependent children in the household, no insurance or private insurance without drug coverage, and more chronic conditions. Sensitivity analyses restricted to adults with incomes $<200 \%$ FPL revealed similar results in a smaller sample (eAppendix Table C).

\section{Discussion}

In this nationally representative sample of adults with chronic disease, food insecurity and cost-related medication underuse were common, with $22 \%$ reporting 
food insecurity or cost-related medication underuse. Another $11 \%$ reported both food insecurity and cost-related medication underuse. The high overall prevalence of food insecurity and cost-related medication underuse highlights how difficult successful chronic disease management in the current social environment is. These findings suggest residual unmet needs for food insecure participants and thus have clear implications for health policy. Additionally, our finding that respondents with incomes from $100 \%-200 \% \mathrm{FPL}$, an income range associated with the phase out of many means-tested benefits, report high rates of food insecurity and cost-related medication underuse may be an important consideration when setting program eligibility rules.

We report an association between public insurance programs, such as Medicaid, and lower cost-related medication underuse compared to private insurance prescription benefits. This likely reflects the lower levels of cost-sharing, such as lower co-payments, in Medicaid plans. Low or no-cost sharing prescription drug benefits have been associated with improved health outcomes in a general population(18), as well as the reduction of socioeconomic disparities in health outcomes(19). Similarly, we found that patients enrolled in WIC had a lower prevalence of food insecurity and cost-related medication underuse. While the WIC program serves a population different from many chronically ill Americans, it may be useful to investigate whether aspects of the program itself are particularly effective in reducing economic insecurity. The observation that Medicaid and WIC participation is associated with lower odds of both food insecurity and cost-related medication underuse suggest that there may be important 'spill-over' effects from 
programs that target food insecurity or cost-related medication underuse, by freeing up available resources. Interestingly, SNAP participation was associated with higher rates of food insecurity. Prior analyses have also noted greater food insecurity in SNAP participants compared to income-matched non-participants, which is often attributed to self-selection into the program(20).

Our analysis identified particular population subgroups that, when faced with insufficient resources to meet both food and medication needs, were more likely to report food insecurity rather than cost-related medication underuse and vice versa. These patient groups may particularly benefit from targeted interventions. Specifically, Hispanic and non-Hispanic black participants with insufficient resources were more likely to report food insecurity while following their prescribed treatment plan, which may represent an unforeseen harm of medical interventions. Alternatively, those with more chronic conditions and dependent children are more likely to forgo needed medications-with potentially important consequences both for their own health and for their children if their health worsens. This is consistent with observations that caregivers are less likely to adhere to their medications(21).

Because of these findings, clinicians should be attuned to the difficult tradeoffs between food and medication related expenses that patients face. It is also worthwhile to keep in mind the larger social context of the patient's worldchildren, relatives, and others to whom the patient devotes scarce resources. Assessing for both household food insecurity and cost-related medication underuse, especially in patients from groups at high risk, may be warranted. If identified, 
engagement of the patient in state, local, or private (such as pharmaceutical company based) benefit programs may help reduce the burden of competing choices. However, the ability of individual clinicians to rectify unequally distributed social determinants of health is limited. We need organized, broad-based support for multidisciplinary programs to improve social determinants in vulnerable populations.

Our analysis is consistent with and expands upon prior work. In an analysis from a representative population-based sample of Californians with diabetes, Billimek and Sorkin(22) found that food insecurity was associated with one component of cost-related medication underuse, delays in filling prescriptions. However, whether this was generalizable to other patient populations or other domains of cost-related medication underuse was previously unknown. Work by Kushel et al.(23) demonstrated that food insecurity was associated with increased acute care utilization such as emergency department visits, using data on lowincome families drawn from a nationally-representative population-based sample, which suggests one possible consequence of cost-related medication underuse. An analysis of Medicare participants(4), before and after Medicare Part D implementation, found that prescription drug coverage increased disposable income available for 'basics' such as food. Also consistent with prior work(24), we observed that educational attainment is not associated with cost-related medication underuse alone, but is associated with food insecurity (and food insecurity plus cost-related medication underuse). The reasons for this apparent discrepancy are not entirely clear. It may be that those with chronic illness and lower educational attainment 
receive assistance in enrolling for prescription drug benefits when they contact the healthcare system, while there is less assistance in accessing the safety-net for food insecurity. Alternatively, the positive association between lower education and food insecurity may represent residual confounding.

NHIS data are cross-sectional and observational, which prevent us from evaluating time ordering or establishing cause. For example, the association between SNAP participation, food insecurity and cost-related medication underuse most likely represents confounding by indication—-those participating in SNAP are the more severely under-resourced-rather than a causal association between SNAP and cost-related medication underuse. Despite this inability to generate causal inference, our results do demonstrate that food insecure adults are a group with high rates of cost-related medication underuse, and may particularly benefit from targeted interventions for both food insecurity and cost-related medication underuse. Next, because participants were not directly asked whether they sacrificed food for medications, or medications for food, we cannot be sure of the reason a food or medication need went unmet. Nevertheless, identifying groups that are more likely to have food insecurity when their medication needs are met, or vice versa, may be important for targeting policies to these vulnerable groups. Another limitation is that clinical outcomes, such as laboratory measurements or healthcare records, are not available in the NHIS dataset. Finally, reporting cost-related medication underuse may be subject to social desirability bias. However, there is no reason to suspect a differential effect on reporting. 
These limitations however, are balanced by several strengths. Our analysis used data collected from a nationally representative, population-based sample with well-validated items. The large effect size after adjustment makes residual confounding a less likely explanation for the observed associations. Finally, food insecurity represents an easily identifiable risk factor for cost-related medication underuse. Because several programs are known to improve both cost-related medication underuse and health outcomes $(18,19)$, it may be worth evaluating whether utilizing food insecurity as an eligibility criterion for similar programs could help improve health in chronically ill patients with food insecurity.

In conclusion, food insecurity is strongly associated with cost-related medication underuse, and approximately 1 in 3 chronically-ill NHIS participants are unable to afford food, medications, or both, despite participation in assistance programs. Interventions targeted to under-resourced groups who may face 'treat or eat' choices could produce substantial health gains for these vulnerable patients. 


\section{References}

1. Ward B, Schiller J, Freeman G, Peregoy J. Early release of selected estimates based on data from the January-September 2012 National Health Interview Survey. National Center for Health Statistics; March 2013.

2. Gallup Healthways. Gallup-Healthways Monthly U.S. Well-Being Report - April 2012. 2012.

3. Piette JD, Heisler M, Wagner TH. Cost-related medication underuse among chronically ill adults: the treatments people forgo, how often, and who is at risk. Am J Public Health. 2004;94(10):1782-7.

4. Madden JM, Graves AJ, Zhang F, et al. Cost-related medication nonadherence and spending on basic needs following implementation of Medicare Part D. JAMA. 2008;299(16):1922-8.

5. Coleman-Jensen A, Nord M, Andrews M, Carlson S. Statistical Supplement to Household Food Security in the United States in 2011. In: U.S. Department of Agriculture Economic Research Service, editor. 2012.

6. Bickel G, Nord M, Price C, et al. Guide to Measuring Household Food Security, Revised 2000. In: U.S. Department of Agriculture Food and Nutrition Service, editor. Alexandria VA2000.

7. Pan L, Sherry B, Njai R, Blanck HM. Food insecurity is associated with obesity among US adults in 12 states. J Acad Nutr Diet. 2012;112(9):1403-9.

8. Parker ED, Widome R, Nettleton JA, Pereira MA. Food security and metabolic syndrome in U.S. adults and adolescents: findings from the National Health and Nutrition Examination Survey, 1999-2006. Ann Epidemiol. 2010;20(5):364-70.

9. Seligman HK, Laraia BA, Kushel MB. Food insecurity is associated with chronic disease among low-income NHANES participants. J Nutr. 2010;140(2):304-10.

10. Seligman HK, Schillinger D. Hunger and socioeconomic disparities in chronic disease. N Engl J Med. 2010;363(1):6-9.

11. National Center for Health Statistics. About the National Health Interview

Survey. Centers for Disease Control,; 2013 [10 Feb 2013]; Available from:

http://www.cdc.gov/nchs/nhis/about nhis.htm.

12. Division of Health Interview Statistics National Center for Health Statistics.

NHIS Survey Description. Hyattsville, MD: Centers for Disease Control; 2012.

13. Agency for Healthcare Research and Quality. Medical Expenditures Panel Survey (MEPS). 2004 [11 Feb 2013]; Available from:

http://meps.ahrq.gov/mepsweb/survey_comp/survey.jsp.

14. Soumerai SB, Pierre-Jacques M, Zhang F, et al. Cost-related medication nonadherence among elderly and disabled medicare beneficiaries: a national survey 1 year before the medicare drug benefit. Arch Intern Med. 2006;166(17):1829-35.

15. Kaiser Family Foundation. Number of Medicare Beneficiaries with Creditable Prescription Drug Coverage, by Type. [8 May 2013]; Available from: http://kff.org/medicare/state-indicator/medicare-rx-drug-coverage/.

16. Kaiser Family Foundation. Medicaid Benefits: Prescription Drugs. [8 May 2013];

Available from: http://kff.org/medicaid/state-indicator/prescription-drugs/\#.

17. National Center for Health Statistics. 2011 National Health Interview Survey (NHIS) 
Public Use Data Release Hyattsville, Maryland Centers for Disease Control and Prevention

U.S. Department of Health and Human Services; 2012.

18. Choudhry NK, Avorn J, Glynn RJ, et al. Full coverage for preventive medications after myocardial infarction. N Engl J Med. 2011;365(22):2088-97.

19. Booth GL, Bishara P, Lipscombe LL, et al. Universal drug coverage and socioeconomic disparities in major diabetes outcomes. Diabetes Care. 2012;35(11):225764.

20. Wilde PE. Measuring the effect of food stamps on food insecurity and hunger: research and policy considerations. J Nutr. 2007;137(2):307-10.

21. Shrank WH, Liberman JN, Fischer MA, et al. Are caregivers adherent to their own medications? J Am Pharm Assoc (2003). 2011;51(4):492-8.

22. Billimek J, Sorkin DH. Food insecurity, processes of care, and self-reported medication underuse in patients with type 2 diabetes: results from the California Health Interview Survey. Health Serv Res. 2012;47(6):2159-68.

23. Kushel MB, Gupta R, Gee L, Haas JS. Housing instability and food insecurity as barriers to health care among low-income Americans. J Gen Intern Med. 2006;21(1):717.

24. Zivin K, Ratliff S, Heisler MM, et al. Factors influencing cost-related nonadherence to medication in older adults: a conceptually based approach. Value Health. 2010;13(4):338-45. 
Clinical Significance:

- Cost-related medication underuse and food insecurity are common among chronically ill adults, with $1 / 3$ of patients reporting one or both

- Food insecurity is strongly associated with cost-related medication underuse

- Racial/ethnic minorities and adults with more co-morbidities are more likely to report food insecurity and cost-related medication underuse. Participation in programs like Medicaid and WIC is associated with less cost-related medication underuse and food insecurity 
Table 1: Demographics

\begin{tabular}{|c|c|c|c|c|c|c|}
\hline & $\begin{array}{l}\text { Overall } \\
n=9696\end{array}$ & $\begin{array}{l}\text { Neither } \\
\text { Food } \\
\text { Insecure nor } \\
\text { CRMU } \\
n=6441\end{array}$ & $\begin{array}{l}\text { Food } \\
\text { Secure but } \\
\text { CRMU } \\
n=1258\end{array}$ & $\begin{array}{l}\text { Food } \\
\text { Insecure } \\
\text { but no } \\
\text { CRMU } \\
n=908\end{array}$ & $\begin{array}{l}\text { Both Food } \\
\text { Insecure and } \\
\text { CRMU } \\
n=1082\end{array}$ & $\overline{p \text {-value }}$ \\
\hline & $\begin{array}{l}\% \text { or } \\
\text { mean } \\
(\mathrm{se})\end{array}$ & $\begin{array}{l}\% \text { or mean } \\
(\mathrm{se})\end{array}$ & $\begin{array}{l}\% \text { or mean } \\
(\mathrm{se})\end{array}$ & $\begin{array}{l}\% \text { or mean } \\
(\mathrm{se})\end{array}$ & $\begin{array}{l}\% \text { or mean } \\
(\mathrm{se})\end{array}$ & \\
\hline Age (y) & $\begin{array}{l}60.9 \\
(0.2)\end{array}$ & $64.8(0.2)$ & $53.7(0.4)$ & $54.2(0.6)$ & $49.7(0.4)$ & $<.0001$ \\
\hline Male & 38.8 & 40.0 & 36.3 & 38.1 & 34.6 & .003 \\
\hline $\begin{array}{c}\text { Race/Ethnicity } \\
\text { Hispanic }\end{array}$ & 8.0 & 6.2 & 9.8 & 14.6 & 11.9 & $<.0001$ \\
\hline Non-Hispanic White & 76.4 & 80.9 & 73.7 & 59.5 & 64.0 & \\
\hline Non-Hispanic Black & 12.5 & 9.8 & 13.9 & 22.2 & 20.8 & \\
\hline Asian & 2.0 & 2.3 & 1.5 & 1.8 & 1.4 & \\
\hline Other & 1.0 & 0.8 & 1.1 & 1.9 & 1.8 & \\
\hline $\begin{array}{l}\text { No usual place of care } \\
\text { Insurance }\end{array}$ & 5.8 & 3.3 & 9.9 & 7.7 & 15.8 & $\begin{array}{l}<.0001 \\
<.0001\end{array}$ \\
\hline None & 10.3 & 4.3 & 23.4 & 10.8 & 32.9 & \\
\hline $\begin{array}{l}\text { Private, } w / \mathrm{Rx} \\
\text { coverage }\end{array}$ & 27.2 & 28.5 & 33.1 & 16.6 & 19.5 & \\
\hline $\begin{array}{l}\text { Private, no Rx } \\
\text { coverage }\end{array}$ & 1.3 & 1.3 & 2.3 & 0.6 & 0.5 & \\
\hline Medicare & 38.9 & 46.1 & 26.1 & 21.9 & 21.1 & \\
\hline Public, non-Medicare & 22.3 & 19.7 & 15.0 & 50.1 & 26.0 & \\
\hline Income & & & & & & $<.0001$ \\
\hline$<100 \% \mathrm{FPL}$ & 19.5 & 13.3 & 17.3 & 46.2 & 40.1 & \\
\hline $100-200 \%$ FPL & 22.7 & 18.9 & 26.1 & 30.8 & 36.1 & \\
\hline$>200 \% \mathrm{FPL}$ & 57.7 & 67.8 & 56.6 & 23.0 & 23.8 & \\
\hline Education & & & & & & $<.0001$ \\
\hline$<$ HS Diploma & 20.4 & 18.2 & 17.9 & 34.8 & 26.4 & \\
\hline HS Diploma & 29.8 & 30.1 & 28.5 & 27.4 & 31.8 & \\
\hline > HS Diploma & 49.8 & 51.7 & 53.6 & 37.8 & 41.9 & \\
\hline Born outside US & 9.6 & 9.1 & 8.9 & 13.3 & 10.9 & .0004 \\
\hline SNAP beneficiary & 17.7 & 10.1 & 19.4 & 46.3 & 41.8 & $<.0001$ \\
\hline WIC beneficiary & 2.6 & 1.5 & 4.5 & 5.1 & 5.7 & $<.0001$ \\
\hline Smoking Status & & & & & & \\
\hline Current & 21.5 & 15.0 & 29.6 & 34.5 & 43.7 & $<.0001$ \\
\hline Former & 32.65 & 36.4 & 28.5 & 24.1 & 20.3 & \\
\hline Never & 45.9 & 48.7 & 41.9 & 41.4 & 36.0 & \\
\hline $\begin{array}{l}\text { Number of Chronic } \\
\text { Conditions }\end{array}$ & $\begin{array}{l}2.2 \\
(0.01)\end{array}$ & $2.1(0.02)$ & $2.2(0.04)$ & $2.3(0.05)$ & $2.4(0.05)$ & $<.0001$ \\
\hline
\end{tabular}


CRMU $=$ cost-related medication underuse SNAP $=$ Supplemental Nutrition Assistance Program WIC $=$ Special Supplemental Nutrition Program for Women, Infants, and Children FPL $=$ Federal Poverty Level 
Table 2: Factors associated with Cost-Related Medication Underuse in all chronically-ill participants ( $\mathrm{n}=9696$ )

\begin{tabular}{|c|c|}
\hline & $\mathrm{aOR}(95 \% \mathrm{CI})$ \\
\hline Food Insecure & $4.03(3.44,4.73)$ \\
\hline Age (y) & $0.96(0.95,0.97)$ \\
\hline Male & $0.76(0.67,0.86)$ \\
\hline \multicolumn{2}{|l|}{ Race/Ethnicity } \\
\hline Hispanic & $1.22(0.96,1.54)$ \\
\hline Non-Hispanic White (ref) & $1.0(--)$ \\
\hline Non-Hispanic Black & $1.15(0.98,1.35)$ \\
\hline Asian & $0.90(0.58,1.39)$ \\
\hline Other & $0.92(0.51,1.67)$ \\
\hline No usual place of care & $1.20(0.90,1.61)$ \\
\hline \multicolumn{2}{|l|}{ Insurance } \\
\hline None & $3.38(2.66,4.29)$ \\
\hline $\begin{array}{l}\text { Private, w/ Rx coverage } \\
\text { (ref) }\end{array}$ & $1.0(--)$ \\
\hline Private, no Rx coverage & $1.49(0.86,2.59)$ \\
\hline Medicare & $0.97(0.80,1.19)$ \\
\hline Public, non-Medicare & $0.47(0.37,0.59)$ \\
\hline \multicolumn{2}{|l|}{ Income } \\
\hline$<100 \% \mathrm{FPL}$ & $1.08(0.87,1.35)$ \\
\hline 100-200\% FPL & $1.67(1.40,1.99)$ \\
\hline$>200 \%$ FPL (ref) & $1.0(--)$ \\
\hline \multicolumn{2}{|l|}{ Education } \\
\hline$<$ HS Diploma & $0.86(0.72,1.03)$ \\
\hline HS Diploma & $0.94(0.81,1.09)$ \\
\hline$>$ HS Diploma (ref) & $1.0(--)$ \\
\hline Born outside US & $0.89(0.70,1.14)$ \\
\hline SNAP beneficiary & $1.12(0.90,1.39)$ \\
\hline WIC beneficiary & $0.91(0.65,1.29)$ \\
\hline \multicolumn{2}{|l|}{ Smoking Status } \\
\hline Current & $1.45(1.25,1.70)$ \\
\hline Former & $1.05(0.91,1.22)$ \\
\hline Never (ref) & $1.0(--)$ \\
\hline $\begin{array}{l}\text { Number of Chronic } \\
\text { Conditions }\end{array}$ & $1.41(1.33,1.49)$ \\
\hline
\end{tabular}

*adjusted OR represents multivariable logistic regression results with adjustment for all variables in table ${ }^{* *}$ Bold $=\mathrm{p}<.05$

SNAP $=$ Supplemental Nutrition Assistance Program WIC $=$ Special Supplemental

Nutrition Program for Women, Infants, and Children 
Table 3: Multivariable logistic regression results comparing those reporting food security and no cost-related medication underuse(CRMU) to:

\begin{tabular}{|c|c|c|c|}
\hline & $\begin{array}{l}\text { Both Food Insecure } \\
\text { and CRMU** }\end{array}$ & $\begin{array}{c}\text { Food Insecure but no } \\
\text { CRMUt }\end{array}$ & $\begin{array}{c}\text { Food Secure but } \\
\text { CRMU } \ddagger\end{array}$ \\
\hline & $\mathrm{aOR}(95 \% \mathrm{CI})$ & $\mathrm{aOR}(95 \% \mathrm{CI})$ & $\mathrm{aOR}(95 \% \mathrm{CI})$ \\
\hline Age $(y)$ & $0.94(0.93,0.94)$ & $0.96(0.95,0.97)$ & $0.95(0.95,0.96)$ \\
\hline Male & $0.70(0.58,0.84)$ & $0.98(0.81,1.17)$ & $0.74(0.63,0.87)$ \\
\hline Race/Ethnicity & & & Y \\
\hline Hispanic & $1.58(1.12,2.22)$ & $1.80(1.35,2.39)$ & $1.39(1.05,1.85)$ \\
\hline Non-Hispanic White (ref) & $1.0(--)$ & $1.0(--)$ & $1.0(--)$ \\
\hline Non-Hispanic Black & $1.58(1.24,2.00)$ & $1.64(1.30,2.08)$ & $1.15(0.94,1.39)$ \\
\hline Asian & $1.04(0.54,1.97)$ & $1.02(0.59,1.78)$ & $0.85(0.49,1.47)$ \\
\hline Other & $1.44(0.68,3.08)$ & $1.55(0.77,3.15)$ & $0.90(0.36,2.30)$ \\
\hline No usual place of care & $1.73(1.17,2.56)$ & $1.40(0.92,2.14)$ & $1.30(0.90,1.87)$ \\
\hline \multicolumn{4}{|l|}{ Insurance } \\
\hline None & $3.73(2.70,5.17)$ & $1.10(0.73,1.65)$ & $3.62(2.74,4.78)$ \\
\hline Private, $\mathrm{w} / \mathrm{Rx}$ coverage & $1.0(--)$ & $1.0(--)$ & $1.0(--)$ \\
\hline Private, no Rx coverage & $0.62(0.23,1.71)$ & $0.65(0.25,1.71)$ & $1.68(0.95,2.97)$ \\
\hline Medicare & $1.23(0.88,1.72)$ & $0.96(0.68,1.35)$ & $0.95(0.75,1.20)$ \\
\hline Public, non-Medicare & $0.70(0.50,0.96)$ & $1.48(1.11,1.99)$ & $0.55(0.41,0.72)$ \\
\hline Income & & 皮 & \\
\hline$<100 \%$ FPL & $3.87(2.82,5.33)$ & $3.86(2.92,5.11)$ & $0.89(0.67,1.18)$ \\
\hline $100-200 \%$ FPL & $4.81(3.72,6.20)$ & $3.77(2.94,4.84)$ & $1.71(1.38,2.12)$ \\
\hline$>200 \%$ FPL (ref) & $1.0(--)$ & $1.0(--)$ & $1.0(--)$ \\
\hline Education & 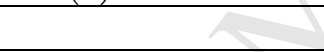 & & \\
\hline$<$ HS Diploma & $0.97(0.7,1.23)$ & $1.39(1.11,1.74)$ & $0.96(0.76,1.22)$ \\
\hline HS Diploma & $1.05(0.85,1.31)$ & $0.95(0.75,1.21)$ & $0.90(0.75,1.08)$ \\
\hline >HS Diploma (ref) & $1.0(--)$ & $1.0(--)$ & $1.0(--)$ \\
\hline Born outside US & $0.98(0.71,1.35)$ & $1.08(0.80,1.46)$ & $0.89(0.63,1.24)$ \\
\hline On SNAP & $1.61(1.25,2.08)$ & $1.82(1.41,2.35)$ & $1.36(1.02,1.81)$ \\
\hline On WIC & $0.39(0.25,0.61)$ & $0.50(0.30,0.84)$ & $0.89(0.58,1.36)$ \\
\hline Smoking Status & + & & \\
\hline Current & $2.01(1.61,2.50)$ & $1.43(1.15,1.79)$ & $1.51(1.25,1.83)$ \\
\hline Former & $0.98(0.79,1.21)$ & $0.92(0.72,1.16)$ & $1.09(0.91,1.31)$ \\
\hline Never (ref) & $1.0(--)$ & $1.0(--)$ & $1.0(--)$ \\
\hline $\begin{array}{l}\text { Number of Chronic } \\
\text { Conditions, per condition }\end{array}$ & $1.56(1.44,1.70)$ & $1.17(1.08,1.27)$ & $1.45(1.36,1.55)$ \\
\hline
\end{tabular}

$*$ Bold represents $\mathrm{p}<0.05$

** Represents results from multivariable logistic regression with 'both food insecurity and cost-related medication underuse' status as dependant variable in a sample of chronically-ill patients with neither $(\mathrm{n}=6441)$ or both $(\mathrm{n}=1082)$

†Represents results from multivariable logistic regression with 'food insecurity but no costrelated medication underuse' status as dependant variable in a sample of chronically-ill patients with neither $(\mathrm{n}=6441)$ or food insecurity but no CRMU $(\mathrm{n}=908)$

$\ddagger$ Represents results from multivariable logistic regression with 'cost-related medication underuse but no food insecurity' status as dependant variable in a sample of chronically-ill patients with neither ( $\mathrm{n}=6441)$ or food secure patients with CRMU $(\mathrm{n}=1258)$ 
Table 4: Associations with report of cost-related medication underuse (CRMU) but no food insecurity compared to report of food insecurity but no CRMU

\begin{tabular}{|c|c|}
\hline & aOR $(95 \% \mathrm{CI})$ \\
\hline Age (y) & $1.00(0.99,1.01)$ \\
\hline Male & $0.84(0.66,1.06)$ \\
\hline \multicolumn{2}{|l|}{ Race/Ethnicity } \\
\hline Hispanic & $0.69(0.47,0.99)$ \\
\hline $\begin{array}{l}\text { Non-Hispanic White } \\
\text { (ref) }\end{array}$ & $1.0(--)$ \\
\hline Non-Hispanic Black & $0.63(0.48,0.83)$ \\
\hline Asian & $0.78(0.40,1.53)$ \\
\hline Other & $0.69(0.29,1.66)$ \\
\hline No usual place of care & $1.09(0.71,1.69)$ \\
\hline \multicolumn{2}{|l|}{ Insurance } \\
\hline None & $2.79(1.85,4.22)$ \\
\hline $\begin{array}{l}\text { Private, w/ Rx } \\
\text { coverage (ref) }\end{array}$ & $1.0(--)$ \\
\hline $\begin{array}{l}\text { Private, no } \mathrm{Rx} \\
\text { coverage }\end{array}$ & $2.79(0.94,8.29)$ \\
\hline Medicare & $0.98(0.67,1.43)$ \\
\hline Public, non-Medicare & $0.38(0.26,0.55)$ \\
\hline \multicolumn{2}{|l|}{ Income } \\
\hline$<100 \% \mathrm{FPL}$ & $0.26(0.19,0.37)$ \\
\hline $100-200 \%$ FPL & $0.42(0.31,0.57)$ \\
\hline$>200 \%$ FPL (ref) & $1.0(--)$ \\
\hline \multicolumn{2}{|l|}{ Education } \\
\hline$<$ HS Diploma & $0.63(0.47,0.84)$ \\
\hline HS Diploma & $0.97(0.74,1.28)$ \\
\hline >HS Diploma (ref) & $1.0(--)$ \\
\hline Born outside US & $0.88(0.59,1.30)$ \\
\hline SNAP beneficiary & $0.75(0.54,1.02)$ \\
\hline WIC beneficiary & $1.49(0.81,2.73)$ \\
\hline Dependent Children & $1.45(1.08,1.96)$ \\
\hline \multicolumn{2}{|l|}{ Smoking Status } \\
\hline Current & $0.98(0.76,1.27)$ \\
\hline Former & $1.16(0.87,1.54)$ \\
\hline Never (ref) & $1.0(--)$ \\
\hline $\begin{array}{l}\text { Number of Chronic } \\
\text { Conditions }\end{array}$ & $1.19(1.09,1.30)$ \\
\hline
\end{tabular}

$*$ aOR $>1$ represents more likely to report CRMU but no food insecurity; aOR $<1$ represents more likely to report food insecurity but no CRMU; Bold $=\mathrm{p}<.05$

**Adjusted OR represents adjustment for all variables in table in a multivariable logistic regression analysis among participants with CRMU but no food insecurity $(n=1258)$ and food insecurity but not CRMU ( $\mathrm{n}=908$ ). 'CRMU but no food insecurity' status was the dependant variable 
SNAP $=$ Supplemental Nutrition Assistance Program WIC $=$ Special Supplemental Nutrition Program for Women, Infants, and Children Appendix 
The NIHMS has received the file 'mmc1.pdf' as supplementary data. The file will not appear in this PDF Receipt, but it will be linked to the web version of your manuscript. 